The Influence of Signs of Social Class on Prosocial Behavior: A Field Experiment Authors: Bennett Callaghan ${ }^{1 *}$, Quinton M. Delgadillo² ${ }^{2}$ \& Michael W. Kraus ${ }^{3}$

\author{
Affiliations: \\ ${ }^{1}$ Yale University, Department of Psychology \\ ${ }^{2}$ Columbia University, Business School \\ ${ }^{3}$ Yale University, School of Management \\ *Correspondence to: Bennett.Callaghan@yale.edu
}

Keywords: Social status, Status signaling, Prosociality, Inequality, Social Class 


\begin{abstract}
A field experiment $(N=4,537)$ examined how signs of social class influence prosocial behavior. In the experiment, pedestrians were exposed to a target wearing symbols of relatively high or low social class in two major urban cities in the USA who was presumably requesting money to help the homeless. Pedestrians gave more than twice (2.55 times) as much to the target wearing high social class symbols than they did to the one wearing lower-class symbols. A follow-up perceptual study exposed participants to images of this panhandler wearing the same higher- or lower-class symbols, finding that higher-class symbols elicited perceptions of elevated competence, trustworthiness, similarity to the self, and perceived humanity compared to lowerclass symbols. These results indicate that perceivers use visible signs of social class as a basis for judging others' traits and attributes, and in decisions to directly share resources.
\end{abstract}




\section{The Influence of Signs of Social Class on Prosocial Behavior: A Field Experiment}

Individuals from various species, ranging from primates to fiddler crabs, signal their social status with nonverbal behaviors and social symbols. Such status symbols assist individuals in avoiding costly aggressive encounters and signal the availability of resources and opportunities that facilitate thriving within groups (Krebs, Davies, \& Parr, 1993; Zeil \& Hoffman, 2001). Generally speaking, a relative lack of opportunity, shorter life spans, and chronic stress accompany low status in various species, humans included (Sapolsky, 2004). Research in the social and economic sciences also suggests that, across the globe, perceivers judge low status individuals - especially those from particularly denigrated groups, such as the poor and homeless — as low in warmth (e.g., untrustworthy), low in competence (e.g., incapable) (Cuddy, Fiske, Glick, \& Xu, 2008; Cuddy, Fiske, \& Glick, 2002), less likely to exhibit human traits, (Laughnan, Haslam, Sutton, \& Spencer, 2014) and as possessing inferior genes (Kraus \& Keltner, 2013). These types of perceptions motivate behaviors of avoidance and ostracism directed toward lower status groups (e.g., Bastian \& Haslam, 2010).

In the present research we examined how symbols of status, particularly those related to the social class position of individuals in society (Kraus \& Keltner, 2009), influence prosocial behavior. We predicted that symbols of high, relative to low, social class would increase prosocial behavior.

Our central prediction is derived from several lines of converging evidence. Several studies suggest that symbols of social class — defined as one's position in society assessed in terms of education, income, and occupation status - are important to the social perceptions and judgments of strangers: When engaging in social comparison processes (Festinger, 1956) people tend to compare their own economic standing to that of others in work contexts (Buunk, 
Zurriaga, Gonzalez-Roma, \& Subirats, 2003). When stereotyping, visual depictions of wealth and poverty predict whether a target will be seen as competent or warm (Fiske, Cuddy, Xu, \& Glick, 2002; Harris \& Fiske, 2008). In research on early person perception, studies reveal that people perceive social class with accuracy based on observable behaviors in 60s interactions with strangers (Kraus \& Keltner, 2009), photographs posted on social media (Becker, Kraus, \& Rheinschmidt-Same, in press), and patterns of pronunciation in brief speech (Giles \& Sassoon, 1983; Labov, 2006).

Additionally, symbols of social class influence prosocial behavior in prior research. In one set of studies, partner social class influenced prosocial intentions and behaviors in economic games more than did participants' own social class (Van Doesum, Tybur, \& Van Lange, 2016). In another, the largest differences in monetary concessions during a negotiation emerged between targets manipulated to wear upper social class symbols (i.e., a business suit purchased at Macy's) and perceivers wearing their own clothing — with perceivers offering more monetary concessions to their upper-class targets (Kraus \& Mendes, 2014).

Several lines of indirect research provide support for our central prediction that symbols of higher social class may elicit greater prosocial behavior than lower-class symbols. People prefer to cooperate with individuals who are perceived to be both warm and competent (e.g., Anderson \& Kilduff, 2012) — a pattern of perception less likely to be associated with targets from the poorest sectors of society (Fiske et al., 2002). Studies also suggest that individuals experience more compassion — an emotion correlated with prosocial behavior — toward suffering others who are more, rather than less, similar to the self (Oveis, Horberg, \& Keltner, 2010). These data suggest that symbols of social class that match perceivers will elicit the highest levels of prosocial behavior. Finally, dehumanization processes, at work for individuals at the bottom of 
the social class spectrum elicit judgments that targets are less worthy of moral consideration and generosity (e.g. Bandura, 2002).

We tested our hypothesis in a field study in urban areas situated in two large metropolitan cities in the USA. Targets solicited donations for the homeless while wearing symbols of lower or upper social class on consecutive days. Since this context — of soliciting donations on public streets - is likely to elicit judgments of low baseline social class our central prediction was informed by the assertion that higher social class symbols will increase beliefs that the target is warm, competent, human, and similar to the self, relative to lower-class symbols. The field study methodology represents a significant advance from prior research given that it examines prosocial behavior in a real world giving context, rather than intentions to donate to hypothetical targets or actual donations in computer simulated interactions.

\section{A Field Study of Social Class and Prosocial Behavior}

Study 1 tested our central hypothesis in a field experiment that sampled pedestrians in an ecologically valid context. Specifically, we expected passersby in six busy locations in downtown urban areas of the USA to behave more prosocially toward a panhandler signaling high status, compared to low status.

\section{Method}

\section{Participants}

Participants for this study consisted of pedestrians in New York City, NY and Chicago, IL that happened to pass a confederate during the course of the study. Spotters, research assistants for the study, were present at each location to record the number of pedestrians (interrater reliability $\mathrm{r}=.99, \mathrm{p}<.001$ ), defined as individuals passing the confederate on the same sidewalk $(\mathrm{N}=4,537)$. We arrived at this eventual sample size in an effort to collect as much data 
as possible. We determined, before each trial began, how long each trial would last, based on the availabilities of the confederate and research assistants. We collected data only during those trials and over the course of the entire trial, except in one instance when the trial was cut short. In one of the high-status trials (Location \#4, See Supplement, Figure 1) the confederate was asked by security to leave his position early, and the confederate complied without incident. We excluded one participant, and his second donation, from the analysis because he happened to encounter the confederate during both conditions.

\section{Procedure}

A single confederate (the study first author) stood at locations where panhandlers and homeless were previously observed while wearing high and low status clothing — one for each social status condition — and holding a cardboard sign with a message about the number of homeless in Chicago or New York. He used a paper coffee cup for collecting donations and occasionally said "Collecting money to help the homeless" in order to draw attention from pedestrians. In the low status condition, the confederate wore jeans and a t-shirt and in the high status condition, a business suit, dress shirt, and tie (see Figure 1, Panel A).

Data were collected for similar amounts of time, on similar days, and in the same locations in the high and low status conditions (see Supplement, Table 1). The locations used in New York City were as follows: (1) E $17^{\text {th }}$ street and Broadway, (2) St. Mark's Place and Avenue A (near the entrance of Tompkin's Square Park); (3) Central Park West between $62^{\text {nd }}$ and $63^{\text {rd }}$ streets; and (4) $56^{\text {th }}$ street and $8^{\text {th }}$ Avenue. In Chicago, they were (5) S. LaSalle between W. Lake street and W. Wacker Drive and (6) W. Jackson Blvd between S. Michigan and S. Wabash streets. 
The confederate was assisted at all locations by two trained spotters-research assistants who were tasked with maintaining the safety of the confederate, counting pedestrians crossing on the same side of the street as the confederate (to determine participation in the study), counting the number of people donating, counting the number of people who interacted with the confederate beyond giving money (such as saying something to him) regardless of whether they donated, and handling any interactions with public law enforcement or security. All collected funds were subsequently donated to a local homeless shelter. For ethical reasons, the confederate did not lie to any of the participants, should they have asked where the money was going, but did not reveal that he was a researcher and that they were participating in a study.

Spotters showed high consistency in their coding of relevant variables: Overall pedestrian counts conducted by spotters overlapped in all cases save for one trial (the low status condition for Location \#2) where the counts differed only by one. Counts for the number of those who donated (coded as seeing a participant physically give money) overlapped $100 \%$ for all trials, and the counts for the number of interpersonal interactions differed by one in two trials (the high status condition for Location \#5 and the low status condition for Location \#6).

Overall generosity in each trial was determined by counting up the total amount donated in US dollars. In each trial, we kept a count of the number of people who donated, but the confederate and spotters could not be certain about the precise dollar amount of each specific donation in every trial—-for example, larger donations of \$5 US were easier to account for than ones of smaller denominations and loose change. In particular, we took note of two $\$ 5$ donations and one $\$ 10$ donation in in Location \#4, and one $\$ 10$ donation in location \#6. All four of these extreme donations occurred during the high status trials. For instances in which analyses call for individual-level data, we estimated the individual values for those who made the remainder of 
the donations by apportioning the amount of unaccounted-for money within a trial equally among the remaining number of people who donated within that trial. For example, we know that, in the high-status trial in Location \#6, one person gave a $\$ 10$ donation, 9 people, in total, gave to the confederate, and the confederate received a total of $\$ 19.51$ during that trial. Following our procedure, then, the data for that trial would consist of $1 \$ 10$ donation, $8 \$ 1.19$ donations ( $\$ 9.51$ divided by 8 ), and the rest coded as 0 . Using these individual scores, we compared and computed the overall means and standard deviations for the high and low status conditions, where necessary.

For the purposes of this study, we define prosocial behavior as both the monetary amount and the frequency of donations that the confederate received in each condition. However, we also report on the number of extreme donations (defined as those of $\$ 5$ and above) and the number of people who went out of their way to interact with the participant, whether they gave money or not, because differences in these two these two variables could suggest qualitative differences in how participants approached the two confederates. The latter measure also disentangles, to some extent, the degree to which potential differences in generosity are due to intentions to engage specifically in prosocial behavior, rather than more general tendencies to approach and interact with the confederate. It should be noted, however, that data on the number of interactions is available only for the trials conducted later in the course of the experiment (specifically, for those trials conducted in Chicago).

\section{Results}

To test our hypothesis about status symbols and generosity, we examined the total amount donated to the confederate as a function of social status condition. In total monetary value (i.e. collapsing across trials and without making assumptions about the size of individual 
donations), the high-status confederate made more than twice as much money (2.55) as the lowstatus confederate over all trials: $\$ 54.11$ (over the course of a cumulative 3.5 hours) compared to $\$ 21.15$ (over 4 hours), $X^{2}(1)=14.44, p=.0001$. We also examined this mean differences as a function of individual donations made by participants. The mean difference amounted to an average of about three cents-per-participant (passerby) across high-status trials $(\mathrm{M}=\$ 0.027, \mathrm{SD}$ $=\$ 0.37)$ compared to less than one cent $(\mathrm{M}=\$ 0.008, \mathrm{SD}=\$ 0.10)$ across low-status trials, $t$ $(4,534)=2.41, p=.02, d=.07$ [95\% CI: .01, .13]. The effect of the manipulation remained, $F(1$, $4532)=6.29, p=.01$, after controlling for the city in which the trials were conducted $\left(\mathrm{M}_{\mathrm{NY}}=\right.$ $\left.\$ 0.024, \mathrm{SD}_{\mathrm{NY}}=\$ 0.32 ; \mathrm{M}_{\mathrm{Chi}}=\$ 0.013, \mathrm{SD}_{\mathrm{Chi}}=\$ 0.22\right), F(1,4532)=1.99, p=.16$, and the interaction between condition and city, $F(1,4532)=0.476, p=.49$. 

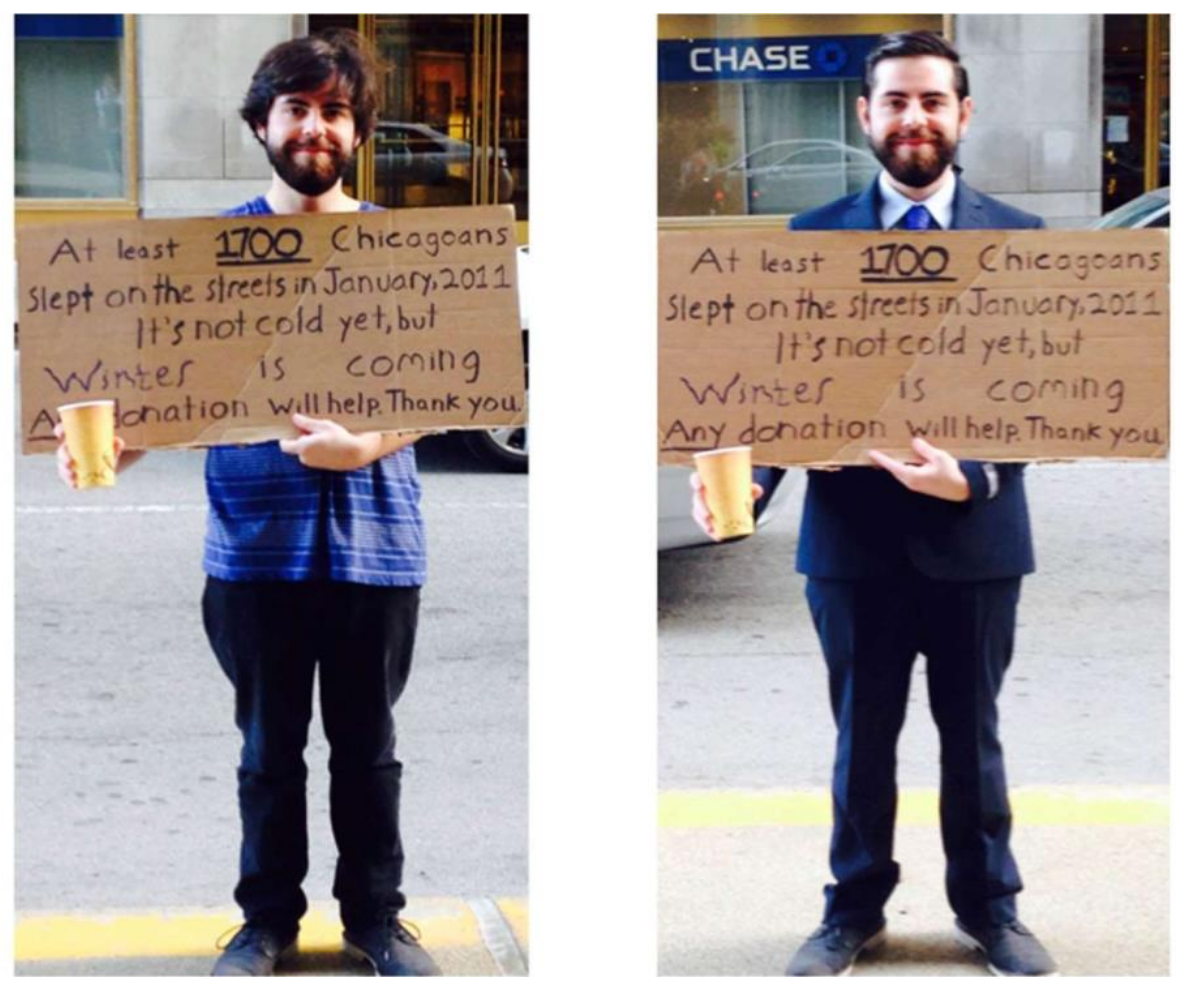

Figure 1. The confederate (the study first author) wearing low-status symbols (left) and highstatus symbols (right) at South Michigan Ave and East Jackson Blvd, Chicago, IL.

Follow-up analyses revealed that similar donation differences emerged both for the number of donors and the distribution of large donations. For the number of donors, we used a contingency table analysis with Fisher's exact test (one-tailed) to examine the distribution of donors in the high- $\left(N_{\text {donors }}=25\right)$, and low- $\left(N_{\text {donors }}=18\right)$ status trials, given the number of participants within each condition $(N=1996$ and $N=2540$, respectively). This analysis revealed that high status trials had a significantly higher proportion of donors than low-status ones, $p=$ .043. We used the same contingency table analysis to examine the distribution of large donations of $\$ 5$ and $\$ 10$, which occurred four times in total, all in the high-status condition. The degree to which the high status trials dominated these large donations differed significantly from what would be expected by chance, $p=0.038$. However, the same analysis applied to the number of 
interactions with the target in the Chicago trials (e.g. saying something to him, regardless of whether they donated) did not differ by condition, $p=.55$, suggesting that the observed differences in prosocial behavior are not solely attributable to people simply noticing and approaching the high-status target more often. ${ }^{1}$ Pedestrians interacted with the high-status $\left(\mathrm{N}_{\text {interactions }}=12\right)$ and low-status $\left(\mathrm{N}_{\text {interactions }}=15\right)$ confederate at roughly equal rates - the main difference emerged, then, with respect to donations.

Importantly, the high-status and low-status trials did not differ in terms of the number of participants, $t(10)=0.54, p=.61$, duration, $t(10)=0$

$.30, p=.77$, start time of the trials, $t(10)=0.46, p=.66$, the ambient temperature at the start of the trials, $t(10)=0.20, p=.85$, or the day of the week on which they fell, $\chi^{2}(3)=2.67, p$ $=.45$ (See Supplement, Table 1 for trial-level data). Thus, any incidental differences among the trials, other than the manipulated experimental variable, are unlikely to have produced the observed effects.

\section{Discussion}

In Study 1, signaling high, compared to low, status drew both more and greater donations from passersby in major urban areas. This advantage emerged despite equivalence across conditions on important variables such as the length of the trials, the number of participants per trial, and the ambient temperature. Thus, this field study supports our first hypothesis: that status signals expressed through sartorial choices directly influence prosocial behavior toward the poor

${ }^{1}$ Limiting the previous analyses only to data collected in the Chicago trials changed the results somewhat. The difference in means $\left(\mathrm{M}_{\text {high }}=\$ 0.021, \mathrm{SD}=\$ 0.31 ; \mathrm{M}_{\mathrm{low}}=\$ 0.006, \mathrm{SD}=\$ 0.10\right)$ reduced, $t(2971)=1.84, \mathrm{p}=.07$, to below levels of conventional significance, but, overall, the high-status (\$27.68) confederate still earned more than twice as much as the low-status one $(\$ 10.50), X^{2}(1)=7.73, p=.005$. Once again, the high-status confederate received more donations $\left(\mathrm{N}_{\text {donors }}=14\right)$ than the low-status one $\left(\mathrm{N}_{\text {donors }}=6\right), p=.02$, and the high-status confederate drew the only extreme donation. However, this latter distribution did not differ from chance, $p=.44$. 
and homeless. Notably, preliminary evidence suggests that these signals do not seem to operate simply by way of increased noticeability or approachability.

The second study, then, was designed to investigate the potential mechanisms by which high-status signaling may elicit greater generosity. In particular, Study 2 tests our hypothesis that low status signals create a negative pattern of social perceptions that decrease the likelihood of providing direct aid.

\section{Study 2: Social Perception Study}

An online follow-up experiment examined the perceptions that elicit these status-driven differences in generosity. Study 2 tested whether those signaling low status were also seen as less competent, less warm, less similar to the self, and less human-all qualities that would dissuade

prosocial behavior and would comport with an interpersonal perception account for the results of Study 1 . In addition, this follow-up study further tested whether, in accordance with an alternative, novelty-based explanation for the results of Study 1, a target asking for money while signaling high status attracted more attention than a similarly solicitous low-status counterpart.

\section{Method}

\section{Participants}

We recruited 500 online participants from Amazon's Mechanical Turk (56\% male and 44\% female). Roughly $75 \%$ of participants identified primarily as White/European-American, $8 \%$ as African-American, 9\% as Asian-American, and 6\% as Latino/a. We collected over 100 participants per condition in order to detect an effect size of $d=0.40$, the average effect size in social psychology, expressed as a difference between two independent means (Richards, Bond, $\&$ Stokes-Zoota, 2003), with $80 \%$ power. Because we measured multiple outcome variables, and previous analyses reveal substantial variation in effect sizes throughout social psychological 
research (Richards et al, 2003), we exceeded this benchmark in order to detect smaller effects and provide more precise point estimates for the effects.

Eight participants were excluded after failing an attention check (identifying what a target in a picture was wearing). Specifically, we asked participants to indicate what the confederate from Study 1 (see Supplement, Figure 1, Panel A and Procedure for more details) wore out of the following four options: (A) Business Suit, (B) T-shirt and jeans, (C) a Hawaiian shirt, and (D) none of the above. We expected those in the low status condition to choose option (B) and for those in the high status condition to choose option (A), and for the most part, they did. Because they were obviously incorrect, we excluded 6 people in the low status condition who chose option (C) and 2 people in the high status condition who chose option (B). However, we perhaps overestimated the consistency with which people would describe the sartorial choices of the target, as 29 and 4 people in the low and high status conditions, respectively, chose option(D). We decided not to exclude anybody who chose option (D) because doing so would introduce differential attrition, and because participants may have subjectively considered the target's clothing to be something other than a business suit or a t-shirt and jeans.

\section{Procedure}

All participants completed a survey they were told attempted to investigate "perception" and involved "looking at images... and giving us your feedback." After providing informed consent, participants viewed images of the confederate from Study 1 and responded to a set of questions concerning him. The target signaled high or low status by appearing dressed in a business suit or jeans and a t-shirt as in Study 1 (see Supplement, Figure 1, Panel A).

Participants in the perception study were first briefly (three seconds) exposed to a wide shot photograph of a street in Champaign, IL that depicted the confederate panhandling on a 
populated street while signaling high or low status. The images were manipulated such that everything except the clothing of the target was equal across conditions (see Supplement, Figure 1, Panel B). Participants were subsequently asked to list up to five things they saw in the photograph.

After listing these items, participants saw a second larger photograph of the target in high or low status clothing (see Supplement, Figure 1, Panel A). Participants then made social perception judgments regarding stereotype content and person perception based on this latter image, which appeared at the top of each page to assist in making judgments. In randomized order, participants were asked to judge the target, absent all other information apart from his physical appearance, on a number of social attributes, including his competence (e.g. “intelligent," "capable”), warmth (e.g. "friendly," "trustworthy"; Cuddy et al, 2002, Cuddy et al, 2008) interpersonal closeness (using the Inclusion of Other in Self scale; Aron, Aron, \& Smollan, 1992), and, finally, a number of items designed to assess the degree to which participants perceived the confederate as possessing human characteristics (Martinez, Piff, Mendoza-Denton, \& Hinshaw, 2011). These constructs were chosen due to their relevance to both status and the receipt of prosocial behavior.

To determine the success of our social status manipulation, participants also ranked the target they saw on a ten-point scale of subjective socioeconomic status used in prior research (Adler, Boyce, Chesney, Cohen, Folkman, Kahn, \& Syme, 1994; Kraus, Tan, \& Tannenbaum, 2013) — wherein participants ranked the target on a 10-rung ladder representing ascending levels of education, income, and occupation status in the USA. Based on this measure of social status position in society (15-16), and consistent with our expectations, the high-status target $(M=$ 3.53, $S D=1.89)$ was judged as considerably higher in social status than the low-status target $(M$ 
$=2.44, S D=1.65), t(482.34)=6.82, p<.001, d=0.61[.43, .80]$. Importantly, and consistent with the experimental context of poverty, both targets were judged to be low in status relative to the scale midpoint $t(246)=-12.20$ and $t(244)=-23.24$, respectively, both $p$ s $<.001$.

\section{Materials}

Noticing the target. We designed the brief exposure task as a way to determine whether the high-status target was more novel or attracted more attention than the lower-status one (presumably because a person panhandling in a suit represents a greater violation of expectations). The first author (blind to condition, except in cases where the participant's answer revealed that the confederate was wearing a suit or appeared homeless - in which case the fact of the participant noticing the confederate is rather unambiguous) used the responses to the brief exposure task to determine whether or not they noticed the target. To do so, the coder read the (up to five) things that participants listed having seen, and judged whether or not they referred to the target; if a participant acknowledged the target at least once over the course of their responses, that participant was given a score of 1 (and a score of 0 otherwise). For example, responses such as "tree" or "man with backpack" would not substantiate noticing the target, whereas responses such as "man asking for money" or "panhandler" would do so. The paper's second author (also blind to condition) independently coded a random subset of 99 responses and scored them in the same manner. The two coders showed adequate reliability $(\kappa=.61)$.

Warmth and competence ratings. Participants were also asked to evaluate the target on dimensions related to warmth (e.g. "friendly", "trustworthy") and competence (e.g. "intelligent", "capable") drawn from previous research that links interpersonal perceptions to societal status (Cuddy et al, 2002, Cuddy et al, 2008). Warmth items reflect the target's perceived trustworthiness and good intentions whereas competence items reflect the target's perceived 
ability to carry out those intentions. Both of these scales also showed high reliability $(\alpha=.95$ and .94 , respectively).

Similarity to the self. Finally, given our prediction that participants would tend to "other" the target and distance him from the self — especially the low-status one-we measured similarity to the self using the Inclusion of Other in Self (Aron et al, 1992) scale by asking participants which pair of increasingly overlapping circles "most closely resemble your relationship with people like [the target]."

Ascribed humanity. We hypothesized that, in addition to seeing the low status target as less warm, less competent, and dissimilar to the self, participants would also tend to see the target as less human — that is, as lacking traits typically associated with humanity and personhood and more traits associated with animality (Laughnan et al, 2014). Consistent with previous research, we refer to this construct as "ascribed humanity" (Martinez et al, 2011). The ascribed humanity index consisted of (a) a shortened version of a humanity scale, asking participants to indicate how much they thought a number of words (e.g. "person," "citizen,") describe the confederate, (b) a shortened animality scale (e.g. "wild," "untamed" [reversecoded]) and (c) their agreement with how much the target embodied personality traits typically considered to be uniquely human: openness to experience (e.g. "open to new experiences, complex") and conscientiousness (e.g. "dependable, self-disciplined"). All three of these scales were drawn from previous research and averaged into a single scale, also consistent with previous research (Martinez et al, 2011). The scale displayed strong reliabilty $(\alpha=.84)$.

\section{Results}

Brief exposure task. Participants were more likely to notice the target in the low-status $(87.4 \%)$ than in the high-status $(74.5 \%)$ condition, $\chi^{2}(1)=13.15, \mathrm{p}<.001$, as determined by 
coding their responses. These results echo those from Study 1, suggesting that the high-status target was not more noticeable than the low-status target. If anything, the former was less noticeable than his low-status counterpart.

Social perceptions. A multivariate analysis of variance revealed that the social status manipulation influenced the hypothesized perceptions of the target, Wilk's $\lambda=.95, F(4,486)=$ 5.96, $p<.001:$ Specifically, participants judged the high-status target as more competent, $F$ $(1,489)=21.35, p<.001, d=0.42[0.24,0.60]$, warmer, $F(1,489)=13.42, p<.001, d=0.33$ $[0.15,0.51]$, more similar to the self $F(1,489)=5.05, p=.025, d=0.20[0.02,0.38]$, and more human, $F(1,489)=9.20, p=.003, d=0.27[0.10,0.45]$ than the low-status one (see Figure 2 and Supplemental Information, Table 2).

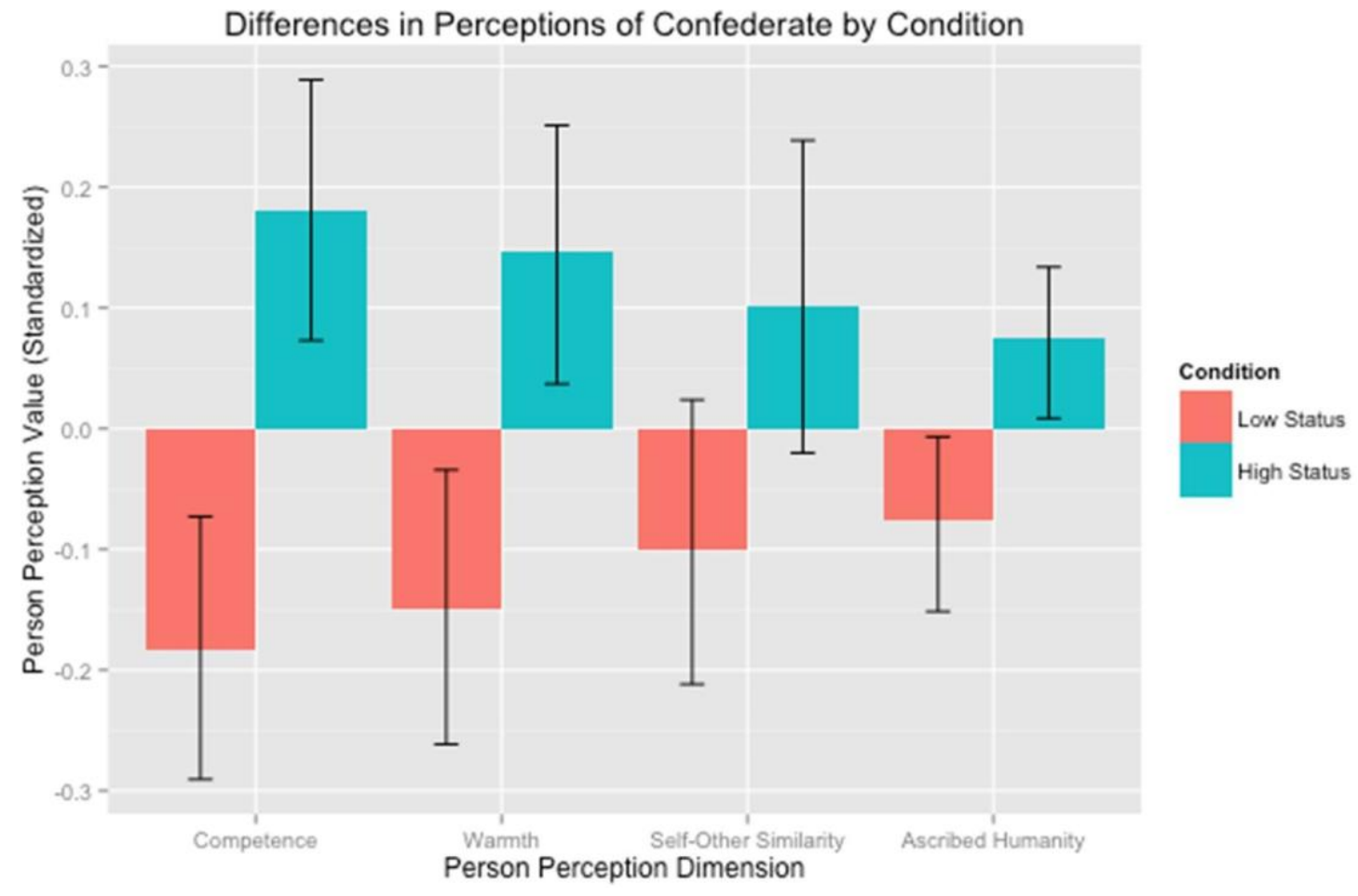


Signs of Social Class and Prosocial Behavior 18

Figure 2. Mean perceptions of high and low status target on dimensions of competence, warmth, self-other similarity, and ascribed humanity. Error bars represent bias-corrected and accelerated (BCa) bootstrapped $95 \%$ confidence intervals with 5000 replications.

\section{Discussion}

Study 2 builds upon the results of Study 1 by outlining the patterns of social perception that guide preferences to share resources with individuals signaling higher status. Specifically, participants judged the low-status target to be less warm, less competent, less human, and less similar to the self. Study 2 also helps to further rule out a more mundane explanation for such preferences and the results of Study 1: that the high-status confederate drew more donations by appearing more novel and simply drawing more attention. That participants were more likely to indicate noticing the low-status target runs counter to the attentional explanation and perhaps suggests greater vigilance of potentially threatening low-status targets (Major \& O’Brien, 2005).

The social perceptions engendered by the low-status target in Study 2 are largely consistent with research showing that people perceive extremely low-status groups in society, relative to their high-status counterparts, as less human (Laughnan et al, 2014), less warm, less competent (Cuddy et al, 2008, Cuddy et al, 2002), and less similar to the self (Kraus \& Keltner, 2013; Bastian \& Haslam, 2010). Moreover, these results provide evidence for the multiple psychological perceptions that arise from perceived social status and drive generosity toward the poor.

\section{General Discussion}

The current research suggests that people respond more prosocially to, and perceive more favorably, individuals who signal higher, relative to lower, social status through physical appearance - even if such individuals still appear to be poor. That these status symbols more 
than doubled the generosity of pedestrians over a four-hour period indicates their power in shaping initial judgments of others' basic human traits and in eliciting prosocial behavioral responses.

Importantly, our results align with past theory and research suggesting that high status signaling provides many direct benefits to individuals, including grooming and mating partners in non-human primates (Sapolsky, 2004). This research adds received generosity to the list of benefits of high status signaling. In essence, high status signals increase judgments of competence, trustworthiness, humanity, and self-other similarity that lead poor individuals who use them to be seen as more effective at converting gifts into desirable outcomes (such as personal advancement or care), and as more likely to use those gifts for intended means, rather than dishonestly, as a strategy to accrue undeserved wealth.

Interestingly, mere novelty and noticeability of the high-status confederate do not seem to explain these differences in generosity. In Study 1, the mere frequency of the interactions did not differ by condition; instead, the quality of the interactions (and the outcomes) seemed to differ, as was the case in our analysis of extreme donations. Anecdotally, this qualitative distinction bears out as well: When people did go out of their way to speak to the confederate, the highstatus one received comments such as "I usually don't give money to people on the street, but you seem like a nice guy." In one case, a pedestrian even dropped a business card into his collection cup. Moreover, Study 2 suggests that, if anything, individuals were more likely to attend to the lower-status target—perhaps because he was seen as threatening.

It is also possible, however, that condition differences in confederate behavior in Study 1 contributed to differences in generosity on the part of the participants. Past research, for example, suggests that donning high-status sartorial signals can change the behavior of naïve 
participants (Kraus \& Mendez, 2014). Though this is a possibility, we did minimize this likelihood by having the confederate behave consistent with standardized instructions. Moreover, that a follow-up study elicited theoretically-relevant patterns of perception from passive observers suggests that the effect of generosity observed in the field is at least partially driven by perceiver judgments.

It is, however, interesting to speculate about how characteristics of the confederate may have impacted the effect of status signaling on generosity. For example, membership in other social categories might modify the results observed in these experiments. Theoretical accounts suggest that symbols of social status influence perception similarly across race and gender (Major \& O'Brien, 2005), but previous research finds that social status and race may interact in subtle ways to produce marked differences outcomes such as health and mortality rates (Case \& Deaton, 2015). Future research might attempt to determine if high status symbols confer the same benefits to other social groups as they apparently do for White males.

Regardless of any possible variation by demographic characteristics of the target, however, this research has direct implications for rising levels of economic inequality in society: Given recent research suggesting that economic inequality increases when social status is more visible (DeCelles \& Norton, 2016; Nishi, Shirado, \& Rand, 2015) the current findings suggest that status symbols expressed through sartorial choices or other nonverbal behaviors are potential mechanisms for the perpetuation of economic inequality. That is, individuals are more likely to enter into economic relationships with individuals who appear higher, rather than lower, in social status. Given these findings, policies aimed at shifting economic inequality by targeting the extremely poor and homeless might receive less support than those targeted at higher status 
members of society in need—such as college students experiencing financial debt—due to judgments of competence, warmth, self-other similarity, and perceived humanity.

Finally, our observed results also add to existing models of compassion and prosociality that highlight sympathy and perceptions of need as primary causes of prosocial behavior (Thomas, 2010). Importantly, our results suggest that, in addition to such emotions, social status - and its accompanying interpersonal judgments - enters prominently into decisions about cooperation and generosity. Ironically, low status individuals who appear to need the most help may end up receiving less of it than those who appear higher in status and more abundant in resources.

Taken together, these findings highlight the power of status symbols to shape our impressions of members of society, even the apparently poor and needy, and highlight how rapidly these perceptions have the potential to shape our social judgments and generosity. Understanding the role of status symbols in shaping initial judgments of others has direct implications for bridging divides between the rich and poor in society, and potentially, for shifting broader political attitudes about the causes and consequences of wealth and poverty. 


\section{Acknowledgments}

Data for the field study and the follow-up perception study are available through the Open Science Framework (https://osf.io/7ej5z/). This material is based upon work supported by the National Science Foundation Graduate Research Fellowship Program under Grant No. DGE1122492. The authors would like to thank Brittany Burns, Brian Kim, Jennifer Mclean, Andi Nault, Rocio Nunez, Adam Stanaland, and Mei Yang for their help in collecting data for the field study. 


\section{References}

Adler, N. E., Boyce, T., Chesney, M. A., Cohen, S., Folkman, S., Kahn, R. L., \& Syme, S. L. (1994). Socioeconomic status and health: The challenge of the gradient. American Psychologist, 49, 15-24.

Anderson, C. \& Kilduff G. J. (2012). The pursuit of status in social groups. Current Directions in Psychological Science, 18, 295-298.

Aron, A., Aron, E. N. \& Smollan, D. (1992). Inclusion of Other in the Self Scale and the structure of interpersonal closeness. Journal of Personality and Social Psychology, 63, $596-612$.

Bandura, A. (2002). Selective moral disengagement in the exercise of moral agency. Journal of Moral Education, 31, 101-119

Bastian, B. \& Haslam, N. (2010). Excluded from humanity: The dehumanizing effects of social ostracism. Journal of Experimental Social Psychology, 46, 107-113.

Case A., \& Deaton, A. (2015) Rising morbidity and mortality in midlife among white nonHispanic Americans in the 21st century. Proceedings of the National Acadamy of Sciences USA, 112, 15078-15083.

Cuddy, A. J. C., Fiske, S. T., Glick, P. \& Xu, J. (2002). A model of (often mixed) stereotype content: Competence and warmth respectively follow from perceived status competition. Journal of Personality and Social Psychology, 82, 878-902.

Cuddy, A. J. C., Fiske, S. T., \& Glick, P. (2008). Warmth and competence as universal dimensions of social perception: The Stereotype Content Model and the BIAS map. Advances in Experimental Social Psychology, 40, 61-150. 
DeCelles, K. A., \& Norton M. I. (2016). Physical and situational inequality on airplanes predicts air rage, Proceedings of the National Academy of Sciences USA, 113, 5588-5591. Goetz, J. L., Keltner, D., \& Simon-Thomas, E. (2010). Compassion: An evolutionary analysis and empirical review, Psychological Bulletin, 136, 351-375.

Kraus, M. W. \& Keltner, D. (2013). Social class rank, essentialism, and punitive judgment. Journal of Personality and Social Psychology, 105, 247-261.

Kraus, M. W., \& Mendes, W. B. (2014). Sartorial symbols of social class elicit class-consistent behavioral and physiological responses: A dyadic approach. Journal of Experimental Psychology: General, 143(6), 2330-2340.

Kraus, M. W., Park, J. W., \& Tan, J. J. X. Signs of social status in brief speech. (under revision).

Kraus, M. W., Piff, P. K., \& Keltner, D. (2009). Social class, sense of control, and social explanation, Journal of Personality and Social Psychology, 97, 992-1004.

Kraus M. W., Tan J. J. X., \& Tannenbaum, M. B. (2013). The social ladder: A rank-based perspective on social class. Psychological Inquiry, 24, 81-96.

Krebs, J. R.,Davies, N. B., \& Parr, J. (1993). An introduction to behavioral ecology (3 ${ }^{\text {rd }}$ Ed). Cambridge: Blackwell Scientific.

Laughnan, S.,Haslam, N., Sutton, R. M. \& Spencer, B. (2014). Dehumanization and social class: Animality in the stereotypes of "white trash," "chavs," and "bogans," Social Psychology, $45,54-61$.

Major, B., \& Obrien, L. T. (2005). The social psychology of stigma. Annual Review of Psychology, 56, 393-421. 
Martinez, A. G., Piff, P. K., Mendoza-Denton, R., \& Hinshaw S. P. (2011). The power of a label: Mental illness diagnoses, ascribed humanity, and social rejection. Journal of Social and Clinical Psychology, 30, 1-23.

National Law Center on Homelessness and Poverty (2014). No safe place: The criminalization of homelessness in U.S. cities. Retrieved from https://www.nlchp.org/documents/No Safe Place

Nishi, A., Shirado, H., \& Rand, D. G. (2015). Inequality and visibility of wealth in experimental social networks, Nature, 526, 426-429.

Oveis, C., Horberg, E. J. \& Keltner , D. (2010). Compassion, pride, and social intuitions of selfother similarity. Journal of Personality and Social Psychology, 98, 618-630.

Rheinschmidt, M. L., Kraus, M. W., \& Keltner, D. (2014). Signaling social class online. Journal of Social Issues (in press).

Richard, F. D.; Bond Jr., Charles F.; Stokes-Zoota, Juli J (2003). One hundred years of social psychology quantitatively described. Review of General Psychology, 7, 331-363.

Sapolsky, R. M. (2004) Social status and health in humans and other animals. Annual Review of Anthropology, 33, 393-418.

United Nations (2015). The Millenium development goals report 2015. Retrieved from http://www.un.org/millenniumgoals/2015_MDG_Report/pdf/MDG\%202015\%20rev\%20 (July\%201).pdf

Zeil, J. \& Hofmann, M. (2001). Signals from 'crabworld': Cuticular reflections in a fiddler crab colony. Experimental Biology, 204, 2561-2569. 


\section{Supplement}
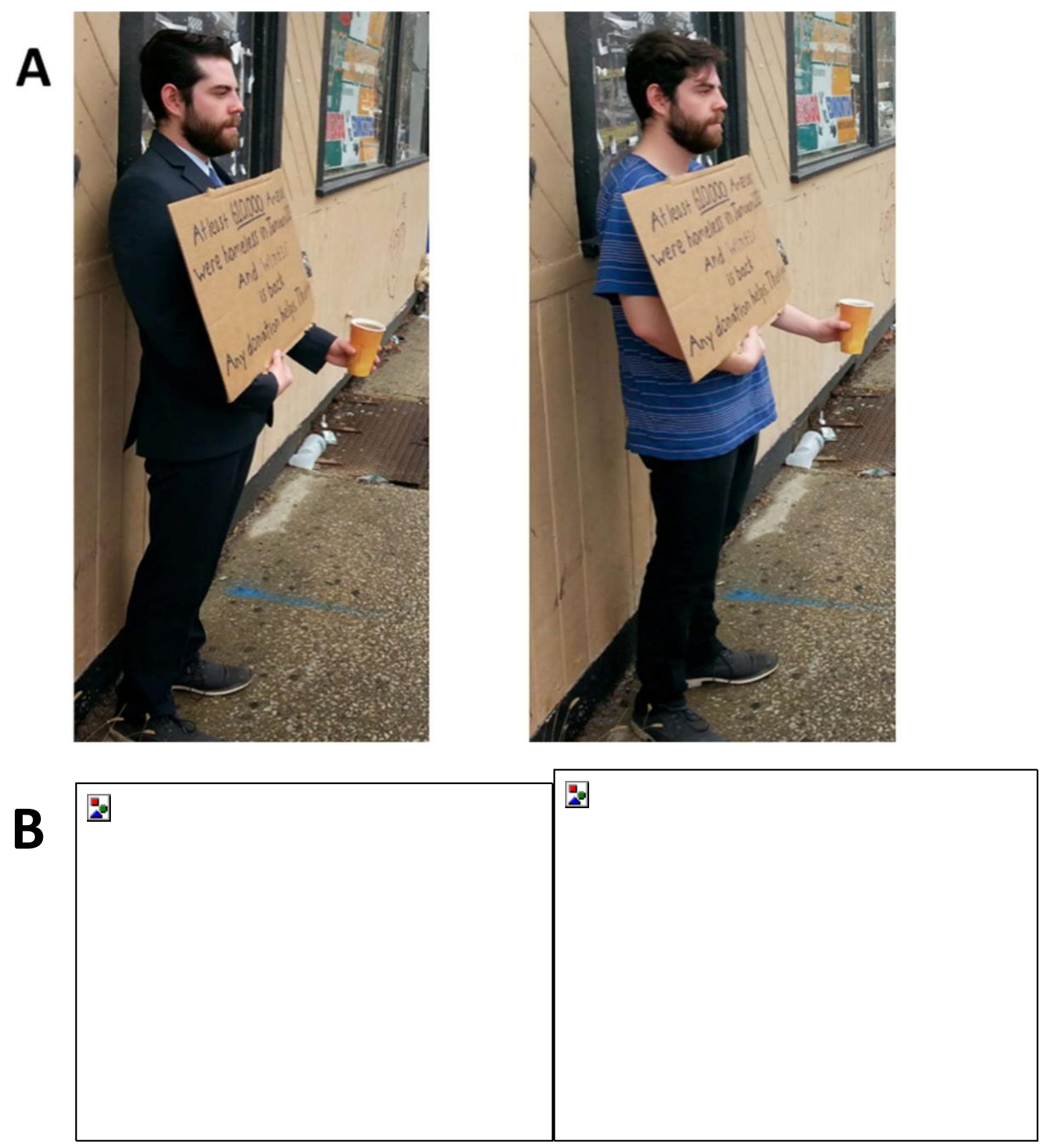

Figure S1. Pictures of the high- and low-status target used in Study 2 for (A) trait ratings and (B) the brief exposure task attention task. 
Table S1. Trial information by location and condition

\begin{tabular}{|c|c|c|c|c|c|c|c|c|c|c|}
\hline City & Location & $\begin{array}{c}\text { Status } \\
\text { Condition }\end{array}$ & $\begin{array}{l}\text { Amount } \\
\text { Collected } \\
\text { (Dollars) }\end{array}$ & $\mathbf{N}$ & Mean $^{a}$ & $\begin{array}{l}\text { Start } \\
\text { Time }\end{array}$ & Duration $^{b}$ & Date & Day & $\begin{array}{c}\text { Temperature } \\
\qquad\left({ }^{\circ} \mathbf{F}\right)^{\mathrm{c}}\end{array}$ \\
\hline \multirow{8}{*}{$\begin{array}{l}\text { New } \\
\text { York }\end{array}$} & \multirow{2}{*}{1} & Low & 1.00 & 259 & 0.004 & $18: 45$ & 15 & $8 / 5 / 14$ & Tuesday & 79 \\
\hline & & High & 0.87 & 184 & 0.005 & $17: 10$ & 15 & $8 / 6 / 14$ & Wednesday & 82.9 \\
\hline & \multirow{2}{*}{2} & Low & 2.65 & 113 & 0.023 & $19: 45$ & 15 & $8 / 5 / 14$ & Tuesday & 78 \\
\hline & & High & 2.00 & 110 & 0.018 & $18: 05$ & 15 & $8 / 6 / 14$ & Wednesday & 82 \\
\hline & \multirow{2}{*}{3} & Low & 1.50 & 228 & 0.007 & $18: 00$ & 15 & 8/7/14 & Thursday & 80.1 \\
\hline & & High & 3.16 & 231 & 0.014 & 18:00 & 15 & $8 / 14 / 14$ & Thursday & 75.9 \\
\hline & \multirow{2}{*}{4} & Low & 5.50 & 273 & 0.020 & $18: 30$ & 45 & 8/7/14 & Thursday & 79 \\
\hline & & High & 20.40 & 165 & 0.124 & $18: 40$ & 25 & $8 / 14 / 14$ & Thursday & 75.9 \\
\hline \multirow{4}{*}{ Chicago } & \multirow{2}{*}{5} & Low & 7.00 & 900 & 0.008 & $16: 35$ & 75 & $9 / 17 / 14$ & Wednesday & 70 \\
\hline & & High & 8.17 & 635 & 0.013 & $16: 40$ & 65 & $9 / 19 / 14$ & Friday & 75.9 \\
\hline & \multirow{2}{*}{6} & Low & 3.50 & 766 & 0.005 & $14: 45$ & 75 & $9 / 26 / 14$ & Friday & 79 \\
\hline & & High & 19.51 & 672 & 0.029 & $14: 45$ & 75 & $9 / 19 / 14$ & Friday & 75 \\
\hline
\end{tabular}

a Total amount divided by $\mathrm{N}$

${ }^{b}$ In minutes

${ }^{c}$ At start of trial: http://www.wunderground.com/history 
Table S2. Means and standard deviations for social perceptions of competence, warmth, selfother similarity, and ascribed humanity, by condition.

\begin{tabular}{cccc} 
Measure & Condition & Mean & SD \\
\hline \multirow{2}{*}{ Competence } & Low Status & -0.18 & 0.87 \\
& High Status & 0.18 & 0.86 \\
\hline Warmth & Low Status & -0.15 & 0.91 \\
& High Status & 0.15 & 0.85 \\
\hline Self-Other & Low Status & 2.26 & 1.34 \\
Similarity & High Status & 2.54 & 1.46 \\
\hline & Low Status & -0.08 & 0.58 \\
Ascribed Humanity & High Status & 0.08 & 0.50 \\
\hline
\end{tabular}

